\title{
Assessment of bone sialoprotein in the saliva of women at peri- and postmenopausal age
}

\author{
Dominika Piątek', Teresa Bachanek', Helena Donica², Renata Chałas ${ }^{1}$ \\ ${ }^{1}$ Department of Conservative Dentistry and Endodontics, Medical University of Lublin, Poland \\ ${ }^{2}$ Department of Biochemical Diagnostics, Medical University of Lublin, Poland
}

Piątek D, Bachanek T, Donica H, Chałas R. Assessment of bone sialoprotein in the saliva of women at peri- and postmenopausal age. J PreClin Clin Res. 2016; 10(2): 100-104. doi: 10.5604/18982395.1227565

\begin{abstract}
Introduction and objective. Bone sialoprotein (BSP) is present in a non-collagenous fraction of bone matrix, in dentine, cement and calcified cartilage. The characteristic place where sialoprotein is produced makes it highly specific in relation to the bone tissue and the possibility of using it as a marker of bone metabolism. The study aimed to assess the BSP level in the saliva of female patients at the menopausal and postmenopausal period.

Materials and method. The study included 71 women aged 45-74 years. In the examined subjects, bone mineral density and bone sialoprotein levels in saliva were determined. Patients also responded to survey questions about place of residence and the frequency of consumption of foods rich in calcium. The obtained results were statistically analyzed.

Results. In the study population of women, BSP saliva concentration ranged from $0.40-14.97 \mathrm{ng} / \mathrm{ml}$. The highest BSP values were observed in the control group (average $-5.66 \mathrm{ng} / \mathrm{ml}$, median $-6.73 \mathrm{ng} / \mathrm{ml}$,), the lowest in the osteopenia group (average $-3.09 \mathrm{ng} / \mathrm{ml}$, median $-1.71 \mathrm{ng} / \mathrm{ml}$ ). This relationship was close to statistical significance $(p=0.056)$. Place of residence of the surveyed women had neither effect on BSP concentration in saliva nor on the value of the T-score ratio. Similarly, there was no statistically significant relationship between the frequency of consumption of foods rich in calcium and BSP and T-score.

Conclusions. It was found that the BSP level can be determined in saliva. Biochemical tests of saliva considering bone metabolism are an issue that should be continued in future, as the availability of material (saliva) for laboratory analyses, carries potential diagnostic opportunities.
\end{abstract}

\section{Key words}

bone sialoprotein, saliva, osteoporosis, bone turnover markers

\section{INTRODUCTION}

Bone sialoprotein (BSP) is phosphorylated glycoprotein with mass $70-80 \mathrm{kDa}$, produced by osteoblasts, odontoblasts, osteoclasts and osteocytes. It was isolated from bovine cortical bone in 1965, and is present in the non-collagenous fraction of bone matrix, in dentine, cement and calcified cartilage $[1,2]$. The characteristic place where sialoprotein is produced makes it highly specific in relation to the bone tissue and the possibility of using it as a marker of bone metabolism. As with most markers of bone turnover, BSP also shows concentration variations - higher levels in the morning and from day-to-day. In healthy subjects, higher concentrations occur during foetal life, early childhood and after menopause $[3,4]$.

Bone sialoprotein constitutes $5-10 \%$ of the total content of non-collagenous proteins in the extracellular matrix of bone. It belongs to the family of low molecular weightbinding integrin ligands, N-linked glycoproteins (SIBLING), which also include: osteopontin, dentin matrix protein 1, dentine sialophosphoprotein and matrix extracellular phosphoglikoprotein. SIBLING proteins lying on the long arm of chromosome 4, through integrins interact with different types of cells and bone minerals. As a result of these interactions, they play an important role in regulating the

Address for correspondence: Renata Chałas, Department of Conservative Dentistry and Endodontics, Medical University of Lublin, Poland

E-mail: renata.chalas@umlub.pl

Received: 12 October 2016; accepted: 2 December 2016 growth, remodeling and repair of bones [5]. High expression of the BSP could be observed in active osteoblasts, and to a lesser extent in odontoblasts and osteoclast-like cell lines and malignant cell lines. BSP contains integrin recognition sequence Arg-Asp-Glyc that facilitates osteoblasts and osteoclasts adhesion to flat surfaces [6] through selective connecting to them. It initiates formation of hydroxyapatite crystals and, as some authors report, bone resorption as well [7].

The role of BSP and its function in bone metabolism has not been fully researched. It is still difficult to determine whether its main role is the process of formation or resorption, or whether it takes part in the 2 phenomena [8]. Although BSP has been primarily isolated from osteoblasts, it has also been detected in osteoclasts and osteoclast-like cell lines and tumour cells. It is suspected that its importance in the initiation of bone resorption is to facilitate the attachment of osteoclasts to the bone. High concentrations of BSP in the plasma of people with metabolic bone diseases, such as Paget's disease, multiple myeloma, or hyperthyroidism, also indicate its importance in the initiation of bone resorption [9].

Osteoporosis is one of the diseases with increased bone metabolism. The frequency of osteoporosis in Poland is estimated at $5.7 \%$ for women at age $45-55$, and at $18.5 \%$ for women over the age of 55 [10]. Due to the costs of treatment of osteoporosis and its complications, especially in the form of fractures (which can lead to permanent disability or death), effective methods for early diagnosis of osteoporosis are still being sought. Diagnosis of osteoporosis is mainly based on the measurement of bone mineral density (BMD) with 
DEXA method [11]. Opinions on the use of bone turnover markers to diagnose progressive osteoporotic process are very cautious. However, in cases where the risk of fractures cannot be determined by other methods, the determination of markers of bone resorption in particular seems to be of great importance. In 2000, the International Osteoporosis Foundation set out the following guidelines for the use of markers [12]:

- where other indicators are inadequate for making a therapeutic decision, the determination of markers may be useful;

- high concentrations of resorption markers are related with an approximately 2 -fold increase in the risk of bone fractures;

- very high concentrations of markers provide information about metabolic disease other than post-menopausal osteoporosis.

For many years, saliva has been used for biochemical tests and in for searching different particles/compounds/ substances characteristic for a given disease. Due to the easy availability of saliva as research material and noninvasiveness of collection, it becomes an important element in the process of diagnosis. Saliva tests may be used to detect Helicobacter pylori infection, HCV, HBV, in the diagnosis of cancers, especially of the breast, ovarian, lung and gastrointestinal tract. Results of the salivary hormone test shows a correlation with the level of the same components in the blood plasma or urine $[13,14,15]$. The accuracy and adequacy of saliva tests for blood analysis makes it a desired research material.

\section{OBJECTIVE}

The research aimed to assess the bone sialoprotein level in saliva of female patients at the peri- and post-menopausal period.

\section{MATERIALS AND METHOD}

The research included 71 women aged $45-74$ years (mean age 58.24 years), with the approval of the Local Ethics Committee in Lublin. In the examined subjects, bone mineral density (BMD) and bone sialoprotein (BSP) levels in saliva were determined. The measurement of BMD using DEXA method was performed in the L2-L4 section of the lumbar spine using a Lunar Prodigy Advance Bone Densitometer (GE Healthcare) in the Densitometry Laboratory of the Institute of Rural Health in Lublin. Biochemical tests of saliva were carried out in the Department of Biochemical Diagnostics, Chair of Laboratory Diagnostics, Medical University in Lublin. Resting, mixed, total saliva sampled from the studied women was centrifuged for 5 minutes at 10,000 rev/min; next, the supernatant was collected and tested. The concentration of bone sialoprotein was determined by an ELISA kit (Immundiagnostik, Bensheim, Germany). BSP content of the samples was calculated from a determined calibration curve and read at a light wavelength of $450 \mathrm{~nm}$.

Patients also responded to survey questions about place of residence and the frequency of consumption of foods rich in calcium and fish.
The obtained results were statistically analyzed. There was a 5\% error of inference and an associated significance level of $\mathrm{p}<0.05$, indicating the existence of significant differences.

\section{RESULTS}

Based on the obtained results of bone mineral density which in the examined group of women ranged from $0.56-$ $1.52 \mathrm{~g} / \mathrm{cm}^{2}$ and adopting the WHO criteria, 3 groups were formed: control group (CTRG) - 17 women with T-score $\geq-1.0$; osteopenia group (OPNG) -23 women with T-score $<-1.0$ and $>-2.5$; and osteoporosis group (OPRG) -31 women with $\mathrm{T}$-score $\leq-2.5$. Mean values of $\mathrm{T}$-scores ratio were 0.05 in CTRG; 1.68 - in OPNG and 3.17- in OPRG, and the differences between groups were significant.

In the examined group of women, BSP concentration measured in the remaining total mixed saliva ranged from $0.40-14.97 \mathrm{ng} / \mathrm{ml}$, and the mean value of BSP for all women was $4.36 \mathrm{ng} / \mathrm{ml}$, median $-2.87 \mathrm{ng} / \mathrm{ml}$. The highest bone sialoprotein concentration in saliva was observed in the control group (mean - $5.66 \mathrm{ng} / \mathrm{ml}$, median $-6.73 \mathrm{ng} / \mathrm{ml}$ ), and the lowest in the osteopenia group (mean $-3.09 \mathrm{ng} / \mathrm{ml}$, median $-1.71 \mathrm{ng} / \mathrm{ml})$. This relationship was close to statistical significance $(\mathrm{p}=0.056)$ (Tab. 1$)$.

Table 1. Bone sialoprotein (BSP) concentration in saliva

\begin{tabular}{|c|c|c|c|c|c|c|c|}
\hline \multirow{2}{*}{$\begin{array}{l}\text { Study } \\
\text { groups }\end{array}$} & \multicolumn{6}{|c|}{ BSP (ng/ml) } & \multirow{2}{*}{$\begin{array}{c}\text { Statistical } \\
\text { analysis }\end{array}$} \\
\hline & Mean & $\begin{array}{l}\text { Standard } \\
\text { deviation }\end{array}$ & Median & $\begin{array}{c}\text { Lower } \\
\text { quartile }\end{array}$ & $\begin{array}{c}\text { Upper } \\
\text { quartile }\end{array}$ & $\begin{array}{l}\text { Range } \\
\text { (min. } \\
\text {-max.) }\end{array}$ & \\
\hline CTRG & 5.66 & 3.46 & 6.73 & 2.75 & 8.74 & $0.76-9.91$ & \multirow{3}{*}{$\begin{array}{l}H=5.77 \\
p=0.056\end{array}$} \\
\hline OPNG & 3.09 & 3.04 & 1.71 & 0.90 & 4.78 & $0.60-10.97$ & \\
\hline OPRG & 4.60 & 4.42 & 2.87 & 1.14 & 7.67 & $0.40-14.97$ & \\
\hline
\end{tabular}

CTRG - control group, OPNG - osteopenia group, OPRG - osteoporosis group

There was no statistically significant correlation between the concentration of BSP and age of the patients.

According to the place of residence of the women - 17 were from villages, 21 from small towns and 33 were living in a big city, no significant relationship was found between women belonging to any of the surveyed groups and their place of residence (Tab. 2). Place of residence also had no effect on BSP concentration in saliva, nor on the value of T-score ratio. Similarly, there was no significant relationship between the frequency of consumption of foods rich in calcium and fish and BSP and T-score (Tab. 3).

Table 2. Place of residence of women in the study population

\begin{tabular}{|c|c|c|c|c|c|c|c|}
\hline \multirow[t]{2}{*}{$\begin{array}{l}\text { Study } \\
\text { groups }\end{array}$} & \multicolumn{2}{|c|}{ Village } & \multicolumn{2}{|c|}{$\begin{array}{l}\text { Small town } \\
(<50,000 \\
\text { inhabitants })\end{array}$} & \multicolumn{2}{|c|}{$\begin{array}{c}\text { City } \\
\text { (> 50,000 } \\
\text { inhabitants) }\end{array}$} & \multirow[t]{2}{*}{$\begin{array}{c}\text { Statistical } \\
\text { analysis }\end{array}$} \\
\hline & $n$ & $\%$ & $n$ & $\%$ & $n$ & $\%$ & \\
\hline CTRG & 7 & 9.86 & 3 & 4.23 & 7 & 9.86 & \multirow{4}{*}{$\begin{array}{l}x^{2}=6.84 \\
p=0.14\end{array}$} \\
\hline OPNG & 4 & 5.63 & 5 & 7.04 & 14 & 19.72 & \\
\hline OPRG & 6 & 8.45 & 13 & 18.31 & 12 & 16.90 & \\
\hline Total & 17 & 23.94 & 21 & 29.58 & 33 & 46.48 & \\
\hline
\end{tabular}

CTRG - control group, OPNG - osteopenia group, OPRG - osteoporosis group 


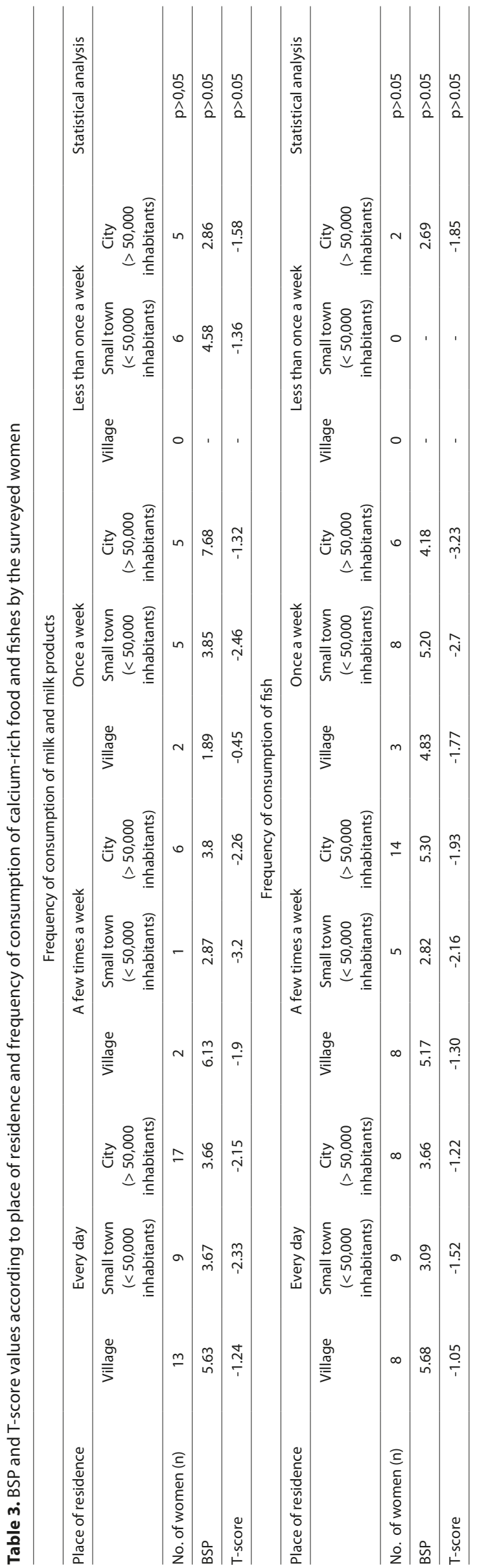




\section{DISCUSSION}

For several years, saliva has constituted an important material useful in medical diagnosis and the monitoring of treatment effects. The easily accessible and non-invasive method of collecting saliva makes it a potential alternative to blood sampling, especially in children or in people whose blood sampling is difficult, for example, in patients with haemophilia. The panel of biochemical tests has been extended to study hormone levels in saliva, which can be used for routine analysis [15].

In recent years, researchers have also made individual attempts to assess the suitability of biochemical tests of saliva in the diagnosis of osteoporosis. In saliva, 2 types of compounds are sought: modulators of expression of the signaling pathway OPG/RANKL/RANK responsible for initiating bone resorption, such as IL-1, IL-11, IL-6, TNF- $\alpha$ [15] and markers of bone turnover, the concentration of which reflects the bone metabolism $[16,17,18,19]$.

The presented study attempts to determine in the saliva of peri- and postmenopausal women the concentrations of bone sialoprotein, the nature of which is not fully understood. This marker is widely considered to be a marker of bone resorption $[4,6,7]$, but there are reports that it can also indicate bone formation $[20,21]$ and that absence of BSP can correlate with delayed initiation of mineralization during the mechanism of bone development [22].

The study was carried out in a population sample of women from the Lublin Region of eastern Poland. Previous studies conducted this region by researchers from the Institute of Rural Health in Lublin were related to: 1) bone mineral density and the prevalence of osteoporosis among women aged 30-79 years [10], 2) differences in the levels of bone turnover markers (OC and CTX), depending on age and BMI in women from rural and urban areas [23], 3) osteoporosis risk factors in woman in the Lublin Region [24], and by researchers from the Medical University of Lublin which were related to osteoporosis risk factors and risk of dental caries in women with osteoporosis $[25,26]$.

Many studies conducted so far have shown that determination of concentrations of bone turnover markers in body fluids (serum, urine) may be a useful method for the diagnosis of osteoporosis [2,27]. Other reports mention a too low specificity of the tests, and the inability to base on them diagnostic criteria for osteoporosis, due to the fact that interpretation of the results presented in the literature refers to the averages for entire groups of patients. Also characteristic is the fact that the rapidly developing osteopenia characterized by a high bone turnover can produce higher results of the test of resorption markers concentrations than osteoporosis. Determination of individual proper concentration level of the marker is a difficult task. Despite such differences of opinions, there are data confirming the high sensitivity and specificity of tests of some markers. These include pyridinoline and deoxypyridinoline, CTx (crosslinked C-telopeptide), which are markers of bone resorption, and ALP, in particular its bone fraction (BSAP), which are markers of bone formation [16]. However, the saliva concentrations of pyridinoline and deoxypiridinoline in patients with osteoporosis were significant higher in comparison with the control group, and osteopenia group [28]. Another study concerning 5-year observations of the relationships between the bone turnover marker saliva concentrations, e.g. HGF, IFN- $\gamma$, IL-1- $\beta$, TNF- $\alpha$,
IL-6, IL-4, IL-8 and osteonectin and ICTP (carboksyterminal telopeptide of type I collagen containing crosslinks), and the loss of alveolar bone mass, found a positive correlation between HGF (hepatocyte growth factor) and IL-1, and a negative correlation between osteonectin and alveolar bone loss. Also, the results obtained by $\mathrm{Ng}$ et al. [18] showed a relationship between higher levels of osteocalcin in stimulated saliva and decreased alveolar bone loss. Another study [19], related to determination of ALP concentration in the saliva of postmenopausal women, revealed significant increase in alkaline phosphatase concentration in the group with osteopenia and osteoporosis, compared to the control group.

Regarding BSP studies, they were mainly based on determination of the levels of this marker in blood serum. Research of Fall et al. [27] showed significantly higher concentrations of BSP in postmenopausal women not taking hormone replacement therapy than in women who took hormone supplementation. Women using HRT and men had similar concentrations of BSP, almost twice lower than the group of women without HRT. Shaarawy et al. [4] found a significant higher level of BSP in postmenopausal women (mean $19.70 \pm 1.04 \mathrm{ng} / \mathrm{ml}$ ), compared to patients in the perimenopausal period $(13.50 \pm 0.95 \mathrm{ng} / \mathrm{ml})$ and reduction in the concentration of the marker after treatment with both HRT, alendronate, and combination of both drugs. They also showed correlations between the concentrations of BSP and markers of bone resorption (Dpyr, Pyr, NTX). Seibel et al. [9] studied the level of BSP in patients with primary hyperparathyroidism, Paget's disease, untreated multiple myeloma and breast cancer and bone metastases. In the study, the BSP level in healthy subjects was included in the range of 5.0-21.6 ng/ml, and for patients with myeloma averaging $30.2 \pm 8.0 \mathrm{ng} / \mathrm{ml}$, and $64.3 \pm 6.8 \mathrm{ng} / \mathrm{ml}$ for patients in the early and late stages of the disease, respectively. A linear correlation was found between the level of BSP and the age of the respondents, but no significant relationship was found between the concentration of the BSP and BMI and BMD. Woitge et al. studied the level of BSP in people with osteoporosis and cancer diseases. In healthy adults, they reported the concentrations of BSP at the level of $10.1 \mathrm{ng} / \mathrm{ml}$ (range 3.4-27.4 ng/ml), in patients with myeloma $27.6 \mathrm{ng} / \mathrm{ml}$, while in patients with osteoporosis it was $18.6 \mathrm{ng} / \mathrm{ml}$ [29]. In contrast to the above-cited authors, Pietschmann et al. [20], in studies conducted in men, showed that the concentration of BSP in the group of patients was approximately 3 -fold lower $(3.7 \pm 0.8 \mathrm{ng} / \mathrm{ml})$ than in healthy controls $(12.4 \pm 4.0 \mathrm{ng} / \mathrm{ml})$. Markers of bone resorption in male subjects exhibited higher concentrations in patients with osteoporosis.

There is limited information about BSP measurement in the oral cavity, and a few of them indicate its presence in cervical-gingival fluid, dentine/cementum and alveolar bone [30]. The presented study shows the presence of BSP in saliva, and the highest level was observed in the control group, and the lowest in patients with osteopenia and osteoporosis. BSP concentration range in the study population amounting to 0.40-14.97 $\mathrm{ng} / \mathrm{ml}$, which was lower than that determined by other authors in the blood serum of healthy people, and with osteoporosis. Studies by Pellegrini et al. [28] also showed lower levels of bone turnover markers determined in saliva, compared to the levels measured in serum and urine; however, on the other hand, studies by various authors have produced different results obtained by the use of different research methods. 


\section{CONCLUSIONS}

In the presented study, BSP was determined in the saliva of the groups of female patients at peri- and postmenopausal age, and showed some differences in saliva bone sialoprotein concentrations between the groups. Because of a small population of women, the interpretation of the results should be treated with some caution and should be followed by a larger study of the significance of these correlations where, f.ex. periodontal status, medications, and lifestyle variables could also be considered. In addition, these data should be compared to those from patients with low and high bone turnover diseases. However, biochemical tests of saliva considering bone metabolism are an important issue that should be continued in future, as the availability of saliva for laboratory analyses carries potential diagnostic opportunities.

\section{REFERENCES}

1.Franzen A, Heinegard D. Isolation and characterization of two sialoproteins present only in bone calcified matrix. Biochem J. 1985; 232(3): 715-724.

2. Störk S, Störk C, Angerer P, Kothny W, Schmitt P, Wehr U et al. Bone sialoprotein is a specific biochemical marker of bone metabolism in postmenopausal women: a randomized 1-year study. Osteoporos Int. 2000; 11(9): 790-796.

3. Seibel MJ. Biochemical markers of bone turnover part I: Biochemistry and variability. Clin Biochem Rev. 2005; 26(4): 97-122.

4. Shaarawy M, Hasan M. Serum bone sialoprotein: a marker of bone resorption in postmenopausal osteoporosis. Scand J Clin Lab Invest. 2001; 61(7): 513-521.

5. Fisher LW, Fedarko NS. Six genes expressed in bones and teeth encode the current members of the SIBLING family of proteins. Connect Tissue Res. 2003; 44: Suppl 1: 33-40.

6. Ross FP, Chappel J, Alvarez JI, Sander D, Butler WT, Farach-Carson $\mathrm{MC}$ et al. Interactions between the bone matrix proteins osteopontin and bone sialoprotein and the osteoclast integrin $\alpha \mathrm{V} \beta 3$ potentiate bone resorption. J Biol Chem. 1993; 268(13): 9901-9907.

7. Valverde P, Tu Q, Chen J. BSP and RANKL induce osteoclastogenesis and bone resorption synergistically. J Bone Miner Res. 2005; 20(9): 1669-1679.

8. Malaval L,Wade-Gueye NM,Boudiffa M,Fei J,Zirngibl R,Chen F et al. Bone sialoprotein plays a functional role in bone formation and osteoclastogenesis. J Exp Med. 2008; 205(5): 1145-1153.

9. Seibel MJ, Woitge HW, Pecherstorfer M, Karmatschek M, Horn E, Ludwig $\mathrm{H}$ et al.: Serum immunoreactive bone sialoprotein as a new marker of bone turnover in metabolic and malignant bone disease. J Clin Endocrinol Metab. 1996; 81(9): 3289-3294.

10. Filip RS, Zagórski J: Bone mineral density and osteoporosis in rural and urban women. Epidemiological study of the Lublin region (Eastern Poland). Ann Agric Environ Med. 2001; 8(2): 221-226.

11. World Health Organization: Assessment of fracture risk and its application to screening for postmenopausal osteoporosis. Technical Report Series 843, Geneva 1994.
12. Osteoporosis Prevention, Diagnosis, and Therapy NIH Consensus Development Panel on Osteoporosis Prevention, Diagnosis, and Therapy. JAMA. 2001; 285(6): 785-794.

13. Pfaffe T, Cooper-White J, Beyerlein P, Kostner K, Punyadeera C. Diagnostic potential of saliva: current state and future applications. Clin Chem. 2011; 57(5): 675-687.

14. Chałas R. Calcium and potassium saliva concentration in patients with multiple sclerosis. Acta Stomatol Croat. 2009, 41(1): 34-38.

15. Humphrey SP, RDH, Williamson RT. A review of saliva: Normal composition, flow, and function. J Prosthet Dent. 2001; 85(2): 162-169.

16. Scannapieco FA, Ng PBY, Hovey K, Hausmann E, Hutson A, WactawskiWende J. Salivary biomarkers associated with alveolar bone loss. Ann N Y Acad Sci. 2007; 1098: 496-497.

17. McGehee JW Jr, Johnson RB. Biomarkers of bone turnover can be assayed from human saliva. J Gerontol. 2004; 101(3): 196-200.

18. Ng PYB, Donley M, Hausmann E, Hutson AD, Rossomando EF, Scannapieco FA. Candidate salivary biomarkers associated with alveolar bone loss: cross-sectional and in vitro studies. FEMS Immunol Med Microbiol. 2007; 49(2): 252-260.

19. Reddy S, Karthikeyan R, Sherlin HJ, Anuja N, Pratibha R, Priya P et al. Oral sings and salivary parameters as indicators of possible osteoporosis and osteopenia in postmenopausal women - A study of 45 subjects. Braz J Oral Sci. 2008; 7(24): 1502-1506.

20. Pietschmann P, Kudlacek S, Grisar J, Spitzauer S, Woloszczuk W, Willvonseder R et al. Bone turnover markers and sex hormones in men with idiopathic osteoporosis. Eur J Clin Invest. 2001; 31(5): 444-451.

21. Fassbender WJ, Ruf T, Kaiser HE, Stracke H. Serum levels of immunoreactive bone sialoprotein in osteoporosis: positive relations to established biochemical parameters of bone turnover. In Vivo. 2000; 14(5): 619-624.

22. Holm E, Aubin JE, Hunter GK, Beier F, Goldberg HA. Loss of bone sialoprotein leads to impaired endochondral bone development and mineralization. BONE. 2015; 71: 145-154.

23. Filip RS, Zagórski J. Age- and BMD-related differences in biochemical markers of bone metabolism in rural and urban women from Lublin Region, Poland. Ann Agric Environ Med. 2004; 11(2): 255-259.

24. Filip RS, Zagórski J. Osteoporosis risk factors in rural and urban women from the Lublin Region of Poland. Ann Agric Environ Med. 2005; 12(1): 21-26.

25. Piątek D, Zubrzycka J, Bachanek T, Filip R. Oral hygiene, health promoting behaviour and awareness of osteoporosis risk factors in over 45-year-old women. Pol J Environ Stud. 2007; 16 Suppl (2C): 437-441.

26. Bachanek T, Piątek D, Zubrzycka J, Filip R. Evaluation of the risk of dental caries in women with osteoporopsis using the Cariogram computer program. 2009; 18 Suppl (1A): 76-79.

27. Fall PM, Kennedy D, Smith JA, Seibel MJ, Raisz LG. Comparison of serum and urine assays for biochemical markers of bone resorption in postmenopausal women with or without hormone replacement therapy and in men. Osteoporos Int. 2000; 11(6): 481-485.

28. Pellegrini GG, Gonzales Chaves MMS, Fajardo MA, Ponce GM, Toyos GI, Lifshitz F et al. Salivary bone turnover markers in healthy pre- and postmenopausal women: daily and seasonal rhythm. Clin Oral Invest. 2012; 16(2): 651-657.

29. Woitge HW, Pecherstorfer M, Horn E, Keck AV, Diel IJ, Bayer P et al. Serum bone sialoprotein as a marker of tumour burden and neoplastic bone involvement and as a prognostic factor in multiple myeloma. $\mathrm{Br}$ J Cancer. 2001; 84(3): 344-451.

30. Campos JM, Prati AJ, Cirano FR, Pimentel SP, Pastore GP, Pecorari VG et al. Smoking Modulates Gene Expression of Type I Collagen, Bone Sialoprotein, and Osteocalcin in Human Alveolar Bone. J Oral Maxillofac Surg. 2015 Nov; 73(11): 2123-2131. 